\title{
The Online Museum: A "Placeless" Space of the "Civic Laboratory" "*
}

\author{
Natalia Grincheva
}

Abstract: Building on Tony Bennett's (1995) understanding of a museum as a "civic laboratory," this study advances this framework by researching a museum space in a virtual world. It shows that an online museum can be understood as a "placeless" space of a "civic laboratory" by analyzing visitor research methodologies that are utilized online. Through comparison of traditional museum-visitor research tools and methods with the ones that online museum spaces employ, this article seeks to demonstrate that the online museum environment is equipped with a plethora of tools that make it a laboratory-type research setting where visitor studies are conducted. The analysis reveals that the historical development of online museum-audience research has gone through methodological stages similar to those of traditional visitor research.

[Keywords: Museum Exhibitions, Research, Theory, Methodology, Evaluation, Ethnography, Behaviorism, Communications Theory. Keywords in italics are derived from the American Folklore Society Ethnographic Thesaurus, a standard nomenclature for the ethnographic disciplines.]

In recent decades, many museums around the world have been actively engaged in establishing an online presence. These virtual museum spaces have been constructed through developing institutional sites on the Internet that provide information about collections or by building interactive environments for presentational, educational, entertainment, or communication purposes. Thus, the term "online museum" is quite broad and inclusive and may refer to a wide spectrum of virtual-museum representations on the Internet. These spaces may include interactive online galleries, virtual three-dimensional museum simulators, museum Web 2.0 profiles on blogs, and social network sites as well as a range of other online and mobile applications that museums have developed to provide interactive activities for their audiences.

Considering the diversity of implied meanings, it is important to give a working definition to the term "online museum" before I proceed with the article. In my research, I would like to focus first of all on the communication dimension of physical museums in a virtual world. By "communication dimension," I mean different online two-way communication settings (social media institutional accounts or profiles, museum blogs, and interactive online collections) that allow audiences to interact with digital museum content and communicate with curators or managers. Thus, within the scope of the present research, the term "online museum" refers to an official Internet representation of a museum on the social web, which serves as an important

\footnotetext{
* This peer-reviewed reviewed contribution was accepted for publication in Museum Anthropology Review on June 19, 2013. The work is licensed under the Creative Commons Attribution 4.0 International License. To view a copy of this license, visit http://creativecommons.org/licenses/by/4.0/.
} 
communication tool that connects the general public with the physical museum and its online collections.

Although new media technologies advanced communication between museums and the public by providing a new means for connection and information exchange, they further problematized a task of museums that has always been important to their institutional nature. This task is to conduct social research on museum visitors that reflects the core function of a museum as a political actor of discipline and control (Bennett 1995). Museums are among the most closely monitored institutional spaces, in which managers employ a number of quantitative and qualitative techniques to observe visitor attendance and behavior. Drawing on the conceptual framework of a laboratory science that Austrian sociologist Karin Knorr-Cetina (1999:38) developed, Tony Bennett (2005) stresses that museums can be understood as "civic laboratories" in that they serve as political sites for national ideology production and promotion by providing a specific public space where "civic experiments" directed at target populations are carefully designed and monitored (2005:525).

Museums, like laboratories, are "social and political structures that 'belong' to their heads in the sense that they are attributed to them and identified with them" (Knorr-Cetina 1999:39). This connection to a larger political structure makes museums accountable social-political building blocks that constitute their significance through acceptable political measurements and evaluation mechanisms. In this sense, museum-visitor research is a core means of political reporting on social progress and performance within larger national communities. Online museums, as an important representational extension of physical institutions in a virtual world, are also heavily involved in conducting constant monitoring of and research on their audiences on the Internet. Thus, online museum spaces, like physical sites, can be understood as major virtual laboratories. Stressing the main aspects of laboratory science that Knorr-Cetina identified, Bennett points out that museums, like laboratories, are not "natural" settings but rather are experimental spaces in which interactions between people and objects "can be arranged for the purpose of both continuous and comparative study" (2005:8). Likewise, in online museum spaces, the "virtual" visitor experience is structured similarly to the "real" visitor experience (Wilson 2011:373).

On the one hand, in an online environment, a visitor can be conceived of "as a spatial wanderer, traversing information and freely selecting trajectories and viewpoints," thus making museum online narratives less directed, linear, and hierarchical than they are in physical exhibition spaces (Cameron 2003:337). On the other hand, cultural theorist Jean-François Lyotard (1984) argues that the notion that digital media foster a democratic relationship between users and institutions through access, interactivity, and multiple narratives is a mere wishful thinking. Instead, he insists that new technologies continue to support established power relationships. Cultural researcher Fiona Cameron stresses that web-design interface and hyperlinking shape visitor behavior online and direct users through a predetermined arrangement of various arguments and counterarguments. In a virtual world, mental processes such as reflection, association, and problem-solving "are materialized rather than internalized through these various modes of representation" (Cameron 2003:337). These materialized cognitive processes result in clicking through links, browsing pages, enlarging details of digital artifacts, and manipulating views of objects. Furthermore, the traces of these online actions are constantly recorded through various 
web applications and can serve as an advanced database of evidence that illustrates visitor behaviors online. In this way, the online museum is not only a mode of representation of a physical museum but also a device that records online visitor-behavior data and a social laboratory where "civic" experiments take place.

Building on the understanding of a museum as a civic laboratory, I aim in this paper to advance this framework by researching a museum space in a virtual world. I intend to show that an online museum can be understood as a "placeless" (Kohler 2002:8) space of a civic laboratory by focusing on the analysis of visitor-research methodologies that museums utilize online. By comparing traditional museum-visitor research tools and methods with the ones that are employed in online museum spaces, this paper seeks to show that the online museum environment is equipped with a plethora of tools that make it a laboratory-type research setting in which visitor studies are conducted.

My analysis demonstrates that the historical development of online museum-audience research has gone through methodological stages similar to those through which traditional visitor research has passed. In traditional visitor research, methodology advanced from the simple quantification of visitor characteristics to complex ethnographic observations that aim at analyzing and interpreting visitors' behaviors in their interactions with objects in a museum setting as well as with each other. This progression is analogous to the evolution of online audience research, which opened with web statistics analytics and has developed to a more comprehensive analysis of online audience engagement with virtual museum content. However, this evolution in both environments refers back to the development of the conception of a museum as a political entity. This political nature of a museum promoted historical progress in advancing research tools and methodologies for the development of the civic laboratory, where social surveillance and manipulation is exercised.

This paper aims to map the evolution of museum-audience research in its historical development through comparative analysis of visitor-research methods that I present in several stages: Quantitative Approach, Behavioral Studies, and Qualitative Enquiry. Each of these sections provides details on the different categories of visitor-research methodologies, comparing and contrasting how researchers utilize them in the physical-museum environment versus the virtual world. Also, each of the sections seeks to reflect the methodological profile of a museum on its laboratorial nature to advance the framework of understanding of online museum as a civic laboratory. In the conclusion, I analyze major results of the historical comparative analysis of museum-visitor studies to illuminate the laboratorial conception of online museum space.

\section{Quantitative Approach}

Eilean Hooper-Greenhill defines "visitor studies" as an umbrella term that encompasses "different forms of research and evaluation involving museums and their actual, potential, and virtual visitors which collectively might be termed the 'audience' for museums" (2006:362). The body of literature on visitor studies has been steadily growing since 2003. A number of scholars have produced several summative studies of visitor research that provide accounts of the history of museum-visitor studies. For example, Ross Loomis compiled a chapter on the development of 
visitor studies before the 1980s in her book Visitor Evaluation: A New Tool for Management (1987). The tradition of connecting visitor studies with educational development in museums, which Loomis advanced in this book, has continued in more recent studies, for example, in one conducted by Hooper-Greenhill (2006). She wrote a historical overview of audience-research development through the evolution of different educational approaches, including behaviorism, cognitivism, and constructivism educational theories.

Some other studies with broad historiographical insight into the visitor-studies field through educational lenses are works by Steve Bitgood (1989), George Hein (1998), Boris Schiele (1992), and Ruth Rentschler and Eve Reussner (2002). These authors suggest that since the emergence of museum studies, a variety of methodologies for studying museum visitors have been proposed and used in many empirical works. Counting, gathering demographics, mapping visitor paths in the museum, surveying audiences, and evaluating visitors' understanding of exhibitions have shaped the majority of museum-visitor studies in the past decades. However, a historical analysis of the field suggests that the progress of these studies was marked by several significant phases that reflected the social agenda of museums within broader political contexts.

The earliest visitor studies gathered quantitative data on museum audiences that reflected the political priority of states to build national surveillance mechanisms to construct a statistical and demographic profile of their population. Historically, in traditional visitor studies, many scholars attempted to quantify specific characteristics of visitors and employ the data to differentiate the museum uses of individuals from various social and demographic groups. According to Bennett, the development of statistical approaches that aim to visualize the social composition of the visiting public is related to the political and economic objective of democratizing museums and making them more socially inclusive (1995:8). In London, the major British museums began gathering audience statistics as early as the 1830s and concentrated on the gross visitor number in different seasons as well as on days of the week (Bennett 1995:8). The recent study by Italian scholar Alessia Zorloni, who interviewed the directors of major museums in London, New York, and Washington, DC, found that the simplest quantitative measures, such as the number of visitors, are still the central and most utilized methodology for measuring museum performance (2010:176).

Studies of demographic profiles of museum visitors that demonstrate their various patterns of use by museums started at the end of the 19th century. As Steve Bitgood indicates, (Rev.) H. H. Higgins conducted the earliest recorded visitor study, collecting data on different types of visitors in 1884 (Bitgood 2002; Higgins 1884). The demographic approach developed fully as a visitor-research methodology almost a century later. During the 1980s and 1990s, there was significant growth in studies of visitors to art museums that were concerned mostly with the statistics of museum visits and the demographic characteristics of audiences, such as the age, gender, ethnicity, and education level of museum visitors (Davies 1994). There were several attempts to survey visitors both by individual museums and by groups of museums. These surveys were based on demographic variables including social class, income, education level, professional affiliation, age, ethnicity, and religion. Researchers believed that these variables could strongly influence visitors' attitudes and opinions about museums (Hooper-Greenhill 2006:368). 
With the development of the Internet, online visitor studies immediately employed the quantitative approach to collecting data on visitors. In many museums, evaluating online audiences has been based on gathering and analyzing statistics that demonstrate unique site visits over a period of time as well as on web demographic data on online visitors. Furthermore, assessing success in social media spaces is also very dependent on quantitative information that demonstrates the number of connections that are created in social networks online (van den Heuvel et al. 2010; Hazan et al. 2010; LaBar 2010). As Barbara Soren (1995) observed in her research on the network of Canadian museums, museums quite frequently track online visitors and compile results in reports over regular intervals (daily, monthly, weekly, annually) in order to evaluate their performance online. In the professional museum world, the audience engagement factor is very often understood in terms of quantitative metrics, such as the number of visits, number of visitors, and the length of time a user spends on a site (Soren 1995:136). This online methodology is heavily influenced by online marketing studies that concentrate on quantitative measures to assess the popularity of products and marketing campaigns (Dawson and Jensen 2011).

In reference to the laboratorial nature of museums, it is important to emphasize that museums, like laboratories, are collective units that encapsulate social and cultural capital that adds to the overall heritage of larger social-political entities such as states. As Knorr-Cetina indicates, neither the tools "nor the system of surveillance is solely contained in the laboratory. ...laboratory also becomes a participant in a larger field of communication and mutual observation" (1999:39). In application to museums, the quantitative statistics gathered in particular museums are very often used to report on the overall picture of national visitorresearch studies. For example, in the United States, evidence from several hundred museums' demographic surveys was compiled collaboratively by Paul DiMaggio, Michael Useem, and Paula Brown in 1977 (1978). McCaughey (1984) carried out a similar survey of 150 Canadian audience studies, most of them audience demographic surveys. In the Netherlands, Ganzeboom and Haanstra 1989 compiles 182 studies statistical report to reevaluate the results in a joint study of national museums (Pearce 1995).

Gathering summative statistics on online and on-site museum visits is a traditional practice now of national cultural heritage departments in many Western countries (Arts Council England 2010; American Association of Museums 2010; Canadian Heritage Information Network 2010). Since most annual museum reports currently provide visitation statistics (for the physical museum as well as the museum's website), "the traffic of information produces a lifeworld within which" museums, the same as "laboratories are locales, but which extends much further" in a national social-political context (Knorr-Cetina 1999:39) and contributes to the construction of a bigger picture of social and cultural demographics.

Though quantitative data indeed point to a social strength and power of museums as social institutions within a political structure of states, they fail to evaluate qualitatively the nature of experiences of online visitors as well as their motivations, interests, and values. In traditional visitor-research studies of the late 1980s, many museum studies scholars criticized the quantification of visitors and museum visits for its irrelevance to measuring the quality of the visitor experience. To address the limitations on understanding museum visitors through 
demographic and statistical data, a behavioral approach in audience research was employed. I discuss this approach in the next section.

\section{Behavioral Studies}

Behavioral studies are based on observing visitor actions within a museum area in order to tackle important issues and phenomena that might occur while visitors explore a museum. The data that help to analyze visitor behavior inside a museum include the total time of a museum visit, choice of exhibition areas, and focus of attention on certain objects or displays. All of these variables change as the visitor proceeds through the exhibition halls of a museum. The importance of this method is closely linked to the understanding of a museum as a laboratory because behavioral studies are predominantly based on reconstructing the physical and cultural spaces of museums in order to analyze the influence of these rearrangements on visitor behavior. Knorr-Cetina argued that "the reconfiguration of both the natural and social orders... constitutes laboratories in crucial ways" (1999:26). Both museums and laboratory practices presuppose the "detachment of objects from their natural environment and their installation in a new phenomenal field defined by social agents" (1999:27). Thus, studying the social influence of these rearrangements within a museum context constitutes an important task of a museum as a political actor. Behavior studies are traditionally linked with research on the educational capacity of a museum to provide an effective learning environment for citizens. Not surprisingly, this learning space is very similar by its nature to a civic laboratory that reconstructs material reality in order to become a place of ideological manipulation of societies.

Tracking visitor movement through exhibit and gallery spaces is one of the oldest methods of studying visitor behavior, dating to the early 1900s. One of the earliest forms of this type of visitor behavioral research is "mapping." Mapping refers to an exhibition evaluation study that is based on observations aimed at tracking the differences between visitor behaviors in particular exhibition spaces. As a result of such observations, maps of tracks are produced that indicate the most and least interesting places of exhibitions according to the time spent at these sites as well as to the number of people who followed similar tracks. Mapping was based on the concept of the "attracting power of the exhibition" that Arthur Melton (1935) and Edward Robinson (1928) developed, defining it as the power of an art installation to attract viewers. It was evaluated by what proportion of visitors stopped to look at a particular artwork or exhibit and by the length of time spent at the spot ("holding power") (Melton 1935:114). Melton also connected the holdingpower effect with the possible influences of two other factors of decreasing attention, "museum fatigue" and "exit attraction," which refer to the desire of visitors to "end exploration, satisfaction of curiosity or a desire to see that which cannot be seen" (1935:114). Benjamin Gilman introduced the term "museum fatigue" earlier, and it was very frequently used in later studies (Gilman 1916).

The use of surveillance technology is very important for using mapping and other behavior studies methodologies in a museum. Like a real laboratory, museums rely on the use of monitoring and recording devices that can help observe people's behavior in real life and collect evidence on visitor activities within a museum. In this way, larger, relatively more sophisticated museums have a strong infrastructural similarity to scientific laboratories. Robert Bechtel (1967) was one of the first scholars to use a technological device to conduct a study of visitors in a 
museum context. He developed the "hodometer" method, which was based on reading the data from a sensitive grid placed under the carpet of a museum hall that triggers electrical contacts through pressure. In this way, an exhibition hall could be measured for frequency of use as the grid indicated the places where visitors stood as well as the length of stay in front of a particular museum object. Interestingly, Bechtel conducted a study to compare the results of this methodology with those of independently carried-out questionnaires that asked visitors about their preferred objects in the museum display. This comparative analysis indicated that verbally expressed preferences for artifacts corresponded to the locations of objects on the floor grid where visitors stopped the most (Bechtel 1967).

With advances in technological development, museums started to utilize a wide range of modern technologies to survey their visitors. One of the methods for studying visitors that is frequently used in museums now is to audiotape people's conversations and videotape their behavior. For example, to study learning processes during museum visits, a group of European scholars audiotaped conversations of visitors in a number of science museums for comparative analysis (Lucas et al. 1986). Kevin Crowley and Maureen Callanan (1998) recorded visitors on video at several exhibitions in the Children's Discovery Museum of San Jose. A collective study of several British museums used videotaping, using direct observations in museum halls to capture and analyze visitors' conversations, body language, and gestures (Vom Lehn et al. 2002). Through observation of body movements and analysis of verbal behavior, all of these studies aimed to analyze visitor responses to particular installation designs in order to assess exhibitions' learning outcomes.

In the online world, the behavior-focused approach has become quite popular among scholars. Online mapping is frequently used to collect online data by tracking visitor paths on websites and by gathering statistics (for example, the number of unique visits to a particular page, the time spent on the page, and the particular browsing path to the page). The data indicate the interest of the visitors in the museum content and point to the most and least popular web pages, galleries, or blog postings. As an Australian group of researchers pointed out in their study evaluating the effectiveness of online communication, an analysis of website statistics can highlight "the pages that are most requested, the average time spent on site and (especially) with popular pages, as well as the main sequence of pages used" (Gillard and Cranny-Francis 2002:38). These patterns of use indicate which parts of websites are most visited and which are seldom selected by different online audiences. This information tells museum managers, and curators how the content that they display online is relevant to visitors' interests and needs and how quickly and easily online visitors can find it.

Online mapping was also used in a great number of more recent studies throughout the world. For example, a group of American scholars used mapping to create a concept map of online exhibits (Douma et al. 2010). Slavko Milekic (2010) explored "gaze-tracking" in online museum environments by studying visitors' paths through online collections. Nate Solas (2010) researched the "findability" of digital objects in online collections by looking at online visitors" browsing consequences. However, online mapping is not the only way to track and survey audience behavior in virtual museum space. Given that online environments are increasingly interactive and provide a lot of tools that allow users to participate, contribute, create, and share, 
looking at how online visitors interact with museum content is another way to study audience behavior online.

From a methodological perspective, observing visitor activities and gathering evidence of their participation and interaction within an online museum space can provide a way to analyze visitors' online behavior. These online activities may include: participation in museum blogs; writing comments and rating posts in social media spaces; collecting, curating, and sharing digital objects in online galleries; or chatting with museum managers online. Whereas video and audio recording are required to collect evidence of visitor behavior in a museum's physical space, an online environment can provide a perfect recording tool in itself because it instantly traces all of the activities of the users and displays all of the visible records that take form in comments, ratings, posts, uploaded video, audio, text and image materials, and so on.

In line with what Knorr-Cetina defines as a "social laboratory," the online museum environment can be seen as a carefully designed space in which to "stage the action" (1999:34). Knorr-Cetina compares social science experimental settings with computer simulations to emphasize that these artificial settings, as behavior-generating experimental situations, design the social reality of objects that interact within those systems. Online museums are similar in many ways to these simulated environments. This similarity is relevant not only because online museums simulate physical museum spaces. Online museums, like social laboratories, are designed according to a theory of nonintervention. As this theory suggests, in order to achieve the maximum correspondence of the simulation to real life "in 'blind' and 'doubleblind' designs, researchers attempt to eradicate the very possibility that they will influence experimental outcomes" (KnorrCetina 1999:35).

In the online world of museum communities, the participants are supposed to become immersed in a world of experiences that create an illusion that every individual has freedom of expression, movement, communication, and choice. Online museum visitors can indeed interact with digital objects as well as with other participants or institutions themselves in numerous unpredictable scenarios. However, this interaction within a particular online museum space is only a simulation of reality and is designed through a complicated system of interfaces that define the level of interactivity of participants and moderate the communication process in public online spaces. In this sense, as Klaus Bruhn Jensen stresses, "the system is the method" (2010:128). Online museum spaces do not require constant monitoring, supervision, or intervention of researchers in the experimental process because the system itself is a monitor, supervisor, data collector, and recording device that instantly archives all the traces of online visitors' activities. In this way, online museum spaces could be compared to social laboratories, which Knorr-Cetina described (1999:35) as spaces designed to be a "one-way mirror" that serves as an observational window to an experimental setup.

On the one hand, an online museum space indeed could be interpreted as a "one-way mirror" type of social laboratory. Online audiences, like experiment participants in a science laboratory, are usually informed that their behavior in online spaces is under observation and that online site providers are collecting personal data that they share online through interactions and contributions. Most online interactive museum spaces (projects, websites, or galleries) as well as all social media channels (such as YouTube, Flickr, Facebook, Twitter) through terms-of-use and 
privacy policies inform their online users that they gather information concerning personal usage of the content through "traffic data" and through feedback that is featured on associated mediasharing and social-media websites. ${ }^{1}$ Furthermore, some of this collected information is publicly accessible and visible on the users' profiles (for example, YouTube video-clips statistics) and even is permitted by the terms and conditions to be disclosed to third parties in an aggregate format. Though online museum goers are indeed informed about these processes of personal data collection, they might not necessarily be aware of what is going on behind the screen in terms of the mechanics, logic, and reasoning of these observations. For example, online museum participants would not know who is observing them in each particular moment of time or how their activities and actions in an online community can be directed or manipulated through changes in the system design.

On the other hand, application of the "one-way mirror" metaphor to online museums suggests a redundant and skewed epistemological paradigm in the behavioral study of museum visitors. The qualitative inquiry, which is described in more detail in the next section, in the historical unfolding of museum-audience research is a more advanced and sophisticated way to research museum visitors online and on site. In contrast with the behavioral framework of research, which conceives of audiences as "passive" or "manipulative," the qualitative paradigm views the museum world more as a "natural" context, where live communities of museum visitors can be studied through ethnographic methods. As Bennett insightfully points out, "In the current flux and fluidity of museum practices... there is a much greater tug-of-war between competing knowledges regarding the arrangement of the relations between objects and persons within the museum space," and "the laboratory situation usually involves a more singular and authoritative manipulation of the relationships between objects than has been true of museums over the last quarter of a century or so" (2005:16).

\section{Qualitative Inquiry}

In addressing various methodological limitations, Hooper-Greenhill criticizes a narrow paradigm of visitor-studies methods that is based on behavior studies and advocates for utilizing a more interpretative research paradigm, one based on cultural-meaning negotiation (2006:362). This paradigm is based on the major findings of mass-communication research in the late 20th century. The most revolutionary concept in defining the development of future audience research was Stuart Hall's seminal work (1973) on how audiences decode media messages. As a result, the scope of empirical efforts advanced understanding of how an audience's cultural, social, economic, religious, and other backgrounds effected its interpretation of media texts. This body of work comprised a radical rethink of the dispersion of power within the media-audience relationship, which gave ground to an emergence of the concept of the "active audience," a term that John Fiske (1987) coined. The media-audience relationship was eventually understood as a complex and multi-faceted phenomenon that depends on a variety of external factors that effect the process of information transfer.

Roger Silverstone was one of the first scholars to contribute to an emerging paradigm for museum evaluation by proposing the use of ethnographic or interpretive methods. He advocated for studies aimed at actual understanding rather than mere measuring (1989:147). If behaviorist 
analyses are concerned with how various factors and designs stimulate visitor response, the ethnographic method aims to understand how cultural environment and artifacts are made relevant in a social relationship within a public discourse. Ethnographic research in a museum space presupposes an analysis of human actions that is based on broader observations of various social, linguistic, cultural, and historical contexts. Only through ethnographic lenses can a researcher of museum visitors grasp the nuances of interaction between a visitor's social sphere and the world of museum objects.

The online ethnographic approach to researching Internet environments developed as a response to the need to study emerging virtual communities, which have been steadily growing since 2003 (Hine 1998). As I suggested earlier, an analysis of online social interaction might make it possible to better understand the complexities of social reality (Paccagnella 1997). David McConnell indicates that it is not a surprise that ethnographic methodology is employed to research computer-mediated communication because an online environment represents an open exploratory setting that is equipped with all of the required tools for observational ethnographic research on virtual communities (2000:72). Online ethnography, known also as cyberethnography, netnography, and virtual ethnography, is a branch of ethnographic studies that aims to study and explore the culture of online communities. It is immersive, descriptive, as multilateral as the traditional ethnographic approach, and utilizes the same methods for analyzing and interpreting data. Online ethnography requires a researcher to become immersed in virtual culture and the life of online participants in order to observe interactions, communication, and community online (Jones 1998). From the marketing perspective, online ethnography is believed to be a significantly faster, easier, and less expensive means of data collection because its methods benefit from freely accessible personal information that people share online (Kozinets 2010), sparing researchers from the need to conduct additional interviews.

As Christine Hine (2000) indicates, online ethnography provides challenges and opportunities for social researchers. The major challenge is to access closed online communities, internal chartrooms, or group forums where members might be discussing sensitive information. However, the main opportunity of online ethnography is that it can provide deeper insight into a range of ideas, thoughts, and emotions: "Virtual ethnography is an adaptive ethnography which sets out to fit itself into the condition in which it finds itself" (Hine 2000:65). Moreover, online ethnography allows researchers (once allowed inside an online community) to go completely covert and in this way avoid any engagement with participants, thus preventing the "behavioral conditioning" that usually biases the results of research.

In application to museum virtual communities, online ethnography can provide a more robust methodological framework than does on-site research that will allow museum managers and scholars to establish practices for researching online visitors' experiences. Online museum communities, whether through a museum blog, social network profile, or specifically designed forum, can be understood as research settings. They are indeed unique environments because they are usually public spaces that allow access to diverse audiences and invite new groups to participate. This openness reflects their cultural-political objective to be more socially inclusive entities than are on-site museums, reaching out to culturally and socially diverse audiences. Nevertheless, the online ethnographic approach has limitations: the research is usually limited to the textual/visual/audio data that people share in communal online spaces, which can exclude a 
significant amount of information that people do not post publicly or that they share through personal messages.

As compared to laboratories, online museums are also based upon the premise that they provide experimental spaces where researchers work "with object images or with their visual, auditory, or electrical traces, and with their components, their extractions, and their 'purified' versions" (Knorr-Cetina 1999:27). The lenses of ethnographic methodology that researchers employ in the virtual museum world reveal especially vividly that social research subjects cannot "be taken as they are" in the online environment, because participants in museum online communities "produce themselves - through typing, writing, image manipulation, creation of avatars, digital video and audio - and engage in practices of everyday life at these interfaces" (Rybas and Gajjala 2007:4). All of these activities serve as "electronic traces" of their personal identities and construct objects of research 'as 'signatures' and 'footprints' of events, rather than as the events themselves” (Knorr-Cetina 1999:41).

In the case of ethnographers who are conducting studies in online museum communities, the laboratorial structure of virtual museums defines their role in the research process as similar to the role of scientists in a scientific laboratory. Knorr-Cetina argues that "scientists are methods of inquiry; they are part of a field's research strategy and a technical device in the production of knowledge (1999:29). Given that an online ethnographer becomes a part of the museum community setting and is "included in the epistemological space of the practice under investigation" (Rybas and Gajjala 2007:4), this involvement invites transformations that make researchers into specific epistemic subjects, who can act as a device "by hearing and seeing signals" (Knorr-Cetina 1999:29). Though the online community is by itself a device of data recording and an archive of evidence on visitor behavior, the role of ethnographer, as a part of this system, is special. An online ethnographer serves as an interpreter who makes sense out of the signals and signs of an online community in the course of its constant articulation of itself through available means of communication. In this way, an ethnographer as a scientific research tool "processing signs" first transmits these signs offline and then reconstructs "the meaning and origin of representations" (1999:40).

Indeed, virtual-museum ethnographers can be understood not only as a part of the "experimental setup" but also as live and active participants in the online museum community. This is because they employ computer mediation, first of all, to observe and, in some cases, even to interact with their research subjects. In order to fully understand what is going on in the world of online interactions among museum visitors and participants, an ethnographer has to "live through" the museum activities and be able to become a part of this world. However, this kind of "participative" observation is rather problematic from the perspective of ethical questions. Hine has suggested that "the Internet provides an ideal opportunity for covert ethnography, since it is possible to lurk in many online environments" (2000:262). Though this so called "unobtrusive research" can grant unique opportunities to study online communities as more "natural" settings (Paccagnella 1997), virtual ethnography as a museum- audience research inquiry raises a lot of ethical problems and challenges.

"Lurking" presupposes first an invisible presence in a site, and many scholars argue that such conduct of research on human subjects is not acceptable since, in this one-way process, a 
researcher acquires a powerful position to gaze on others, "appropriating their actions for the purposes of research," (Heath et al. 1999:451). David Bell, on the other hand, contrasts this covert online-observation methodology with truly ethnographic methods, which emphasize "dialogue with respondents - recasting research as collaboration rather than appropriation" (2001:26). He advocates for implementing specific ethical procedures that oblige a researcher to explicitly disclose his or her research interests and goals to other participants within an online community. These ethical obligations have historically been incorporated in traditional ethnographic museum-research activities (such as focus groups and interviews) that comply with the internationally accepted Code of Ethics for Museums, established by the International Council of Museums (ICOM 2013). However, because virtual ethnography in an online museum space is still a methodological innovation, the professional museum world is experimenting with this new field of research under the guidelines of traditional research practices.

Virtual ethnography as a methodology for collecting information on online users also brings out questions of privacy. Like numerous online communities, including chat rooms, blogs, and discussion groups, specific online-museum projects can be based on the principles of public or private communities. An example of this type of private online museum community is "turbinegeneration," a global online network of art schools that works in cooperation with artists, created by the Tate Gallery (https://turbinegeneration.tate.org.uk/). This is not a publicly accessible platform, where online visitors can easily surf the network. A person must go through a proper registration process that requires disclosure of personal and professional data to get permission to access and interact in the online community. In cases where they are researching audience behavior in such private communities, museum professionals and scholars need to ensure that they conduct their research in an ethical manner, avoiding unauthorized uses of information that they mine in these closed environments.

In a broader framework of virtual ethnography, Chris Mann and Fiona Stewart (2000) established an ethical framework for online research that provides detailed guidelines on consent, confidentiality, and the observance of "netiquette" as well as offering practical advice on how to address these questions in particular cases. An authoritative international organization, the Association of Internet Researchers (2012), also recommends in its guidelines that the ethical implications of online-community research be studied on a case-by-case basis. In the museum studies academic field, the question of ethics in online audience research has not been properly explored yet; only a few articles mention the problematic of ethical issues in a museum-visitor studies framework (Wong 2011; Villaespesa 2013). Yet to be offered is a focused and rigorous approach to this question that provides a productive and meaningful exploration of these issues and establishes required ethical guidelines in an online museum-audience research context.

\section{Conclusion}

This paper has characterized how, throughout the conceptual history of museums and in the history of museum visitor studies research, museums have continued to share many features with science laboratories. In conclusion, I would like to reinforce the laboratorial nature of online museum spaces by highlighting their placelessness. Robert Kohler, in his book "Landscapes and Labscapes" writes: "Since the industrial and social revolutions of the nineteenth century, we [in 
industrial societies] have lived in a culture that values universality over locality, and in such a culture placelessness is a reason to trust" (Kohler 2002:8). He indicates that this human value of universal over local knowledge always pushed laboratories to separate their work from the local cultural specificities of their geographic locations. Furthermore, the modern global nature of laboratories makes them transnational units that operate through international collaborations and involve researchers from a wide variety of countries. This quality also makes them increasingly placeless epistemic spaces. Such a placelessness of modern laboratories advertises "the universality and authority of the culture that builds and inhabits them," as well as serving as a "guarantee of credibility" (2002:9).

The cyber-culture and nature of online museum communities also make them placeless spaces of museums that provide a unique environment that transcends geographic space and time. As Angel Adams Parham asserts, the new media spaces of the Internet create "virtual neighborhoods, no longer bounded by territory, passports, taxes, elections, and other conventional political diacritics" (2005:349). Cross-cultural inclusiveness and the potential diversity of online visitors' cultural-demographic profile in online museum communities make them placeless third spaces where visitors (with Internet access) from around the globe can connect to museum content for learning and interaction. Thus, the online museum is a window on a virtual world of interaction between the museum and social subjects from dispersed geographic locations who are united in a placeless space through technology on the basis of common interests. As this article suggests, these placeless online communities are not only virtual spaces of cultural heritage representation but also important centers of scientific inquiry.

\section{Note}

1. For some examples of online museums' terms-of-use and privacy policies, consult:

Museum of Modern Art, Terms and Conditions: http://www.moma.org/about/about site/, accessed July 4, 2014.

Tate Gallery Privacy Policy: http://www.tate.org.uk/about/who-we-are/policies-andprocedures/website-terms-use/privacy-and-use-cookies, accessed July 4, 2014.

Guggenheim Museum Terms and Conditions of Use: http://www.guggenheim.org/termsconditions/, accessed July 4, 2014.

Canadian Heritage Information Network: "Canada's Got Treasures" Project: Terms Of Use: http://www.museevirtuel-virtualmuseum.ca/sgc-cms/nouvelles-news/anglaisenglish/?page id=285, accessed July 4, 2014.

\section{References Cited}

American Association of Museums 
2010 Service Despite Stress: Museum Attendance and Funding in a Year of Recession. http://www.aam-us.org/docs/research/acme-2010.pdf?sfvrsn=2, accessed July 4, 2014.

Arts Council England

2010 Digital Audiences: Engagement with Arts and Culture Online. http://www.artscouncil.org.uk/media/uploads/doc/Digital_audiences_final.pdf, accessed November 21, 2013.

Association of Internet Researchers (AoIR)

2012 Ethical Decision-Making and Internet Research 2.0: Recommendations from the AoIR Ethics Working Committee. Ethics Guide. http://aoir.org/documents/ethics-guide/, accessed December 1, 2012.

Bechtel, Robert

1967 Hodometer Research in Museums. Museum News 45(7):23-26.

Bell, David

2001 An Introduction to Cybercultures. London: Routledge.

Bennett, Tony

1995 The Birth of the Museum: History, Theory, Politics. London: Routledge.

2005 Civic Laboratories: Museums, Cultural Objecthood and the Governance of the Social. Cultural Studies 19(5):521-547. http://dx.doi.org/10.1080/09502380500365416

Bitgood, Steve

1989 Introduction: Visitor Studies-1988. Visitor Studies 1(1):5-8. http://dx.doi.org/10.1080/10645578809445734

2002 Environmental Psychology in Museums, Zoos, and Other Exhibition Centers. In Handbook of Environmental Psychology. Robert Bechtel and Arza Churchman, eds. Pp. 461-480. New York: John Wiley and Sons.

Cameron, Fiona 
2003 Digital Futures I: Museum Collections, Users, Information Needs and the Cultural Construction of Knowledge. Curator 46(3):325-340. http://dx.doi.org/10.1111/j.21516952.2003.tb00098.x

Canadian Heritage Information Network

2010 Web Analytics-Measuring for Success. http://www.pro.rcip-chin.gc.ca/carrefour-dusavoir-knowledge-exchange/statistiques_sites_web-web_site_stats-eng.jsp, accessed November 21, 2013.

Crowley, Kevin, and Maureen Callanan

1998 Describing and Supporting Collaborative Scientific Thinking in Parent-Child Interactions. Journal of Museum Education 23(1):12-17. http://www.jstor.org/stable/40479111

Davies, Stuart

1994 By Popular Demand: A Strategic Analysis of the Market Potential for Museums and Art Galleries in the UK. London, UK: Museums and Galleries Commission.

Dawson, Emily, and Eric Jensen

2011 Towards a Contextual Turn in Visitor Studies: Evaluating Visitor Segmentation and Identity-Related Motivations. Visitor Studies 14(2):127-140. http://dx.doi.org/10.1080/10645578.2011.608001

DiMaggio, Paul, Michael Useem, and Paula Brown

1978 Audience Studies of the Performing Arts and Museums: A Critical Review. Washington, DC: National Endowment for the Arts.

Douma, Michael, Greg Ligierko, and Joseph Romano

2010 Concept Maps for On-line Exhibits: Using SpicyNodes. In Museums and the Web 2010: Proceedings. Jennifer Trant and David Bearman, eds. Toronto: Archives and Museum Informatics. http://www.archimuse.com/mw2010/papers/douma/douma.html, accessed December 1, 2010.

Fiske, John

1987 Television Culture. New York: Methuen. 
Ganzeboom, Harry, and Folkert Haanstra

1989 Museum and Public: The Public and the Approach to the Public in Dutch Museums. Rijswijk, The Netherlands: Ministry of Welfare, Health and Culture.

Gillard, Patricia, and Anne Cranny-Francis

2002 Evaluation for Effective Web Communication: An Australian Example. Curator: The Museum Journal 45(1):35-49. http://dx.doi.org/10.1111/j.2151-6952.2002.tb00048.x

Gilman, Benjamin

1916 Museum Fatigue. Scientific Monthly 12(1):62-64.

Hall, Stuart

1973 Encoding and Decoding in the Television Discourse. Birmingham, UK: Centre for Contemporary Cultural Studies.

Hazan, Susan, Monika Hagedorn-Saupe, and Rossella Caffo

2010 ATHENA: A Mechanism for Harvesting Europe's Museum Holdings into Europeana. Museums and the Web 2010: Proceedings. Jennifer Trant and David Bearman, eds. Toronto: Archives and Museum Informatics. http://www.archimuse.com/mw2010/papers/angelaki/angelaki.html, accessed December $1,2010$.

Heath, Debora, Erin Koch, Barbara Ley, and Michael Montoya

1999 Nodes and Queries: Linking Locations in Networked Fields on Inquiry. American Behavioral Scientist 43(3):450-463. http://dx.doi.org/10.1177/00027649921955371

Hein, George

1998 Learning in the Museum. London, UK: Routledge.

Higgins, H. H.

1884 Museums of Natural History: Part 1 [of 3]. Museum Visitors. In Transactions of the Literary and Philosophical Society of Liverpool Pp. 185-188. Liverpool: Literary and Philosophical Society of Liverpool. 
Hine, Christine

1998 Virtual Ethnography. Paper presented at the Internet Research and Information for Social Scientists Conference, University of Bristol, March 25-27. http://www.cirst.uqam.ca/pcst3/PDF/Communications/HINE.PDF, accessed December 1, 2010.

2000 Virtual Ethnography. London: Sage.

Hooper-Greenhill, Eilean

2006 Studying Visitors. In A Companion to Museum Studies. Sharon Macdonald, ed. Blackwell Companions in Cultural Studies, 14. Pp. 362-376. Oxford, UK: Blackwell.

ICOM (International Council of Museums)

2013 [1986] Code of Ethics for Museums. http://icom.museum/fileadmin/user_upload/pdf/Codes/code_ethics2013_eng.pdf, accessed November 20, 2013.

Jensen, Klaus Bruhn

2010 Media Convergence: The Three Degrees of Network, Mass, and Interpersonal Communication. Milton Park, Abingdon, Oxon, UK: Routledge.

Jones, Steve

1998 Cybersociety 2.0: Revisiting Computer-mediated Communication and Community. London: Sage.

Knorr-Cetina, Karin

1999 Epistemic Cultures: How the Sciences Make Knowledge. Cambridge, MA: Harvard University Press.

Kohler, Robert

2002 Landscapes and Labscapes: Exploring the Lab-Field Border in Biology. Chicago: University of Chicago Press. http://dx.doi.org/10.7208/chicago/9780226450117.001.0001

Kozinets, Robert V.

2010 Netnography: Doing Ethnographic Research Online. London: Sage.

LaBar, Wayne 
2010 Can Social Media Transform the Exhibition Development Process? Cooking: the Exhibition-An Ongoing Case Study. In Museums and the Web 2010: Proceedings. Jennifer Trant and David Bearman, eds. Toronto: Archives and Museum Informatics. http://www.archimuse.com/mw2010/papers/labar/labar.html, accessed November 20, 2013.

Loomis, Ross

1987 Visitor Evaluation: A New Tool for Management. Nashville, TN: American Association for State and Local History.

Lucas, Aron, Paulette McManus, and Gillian Thomas

1986 Investigating Learning from Informal Sources: Listening to Conversations and Observing Play in Science Museums. European Journal of Science Education 8(4):341-352. http://dx.doi.org/10.1080/0140528860080401

Lyotard, Jean-François

1984 The Postmodern Condition: A Report on Knowledge. Minneapolis: University of Minnesota Press.

Mann, Chris, and Fiona Stuart

2000 Internet Communication and Qualitative Research: A Handbook for Researching Online. London: Sage.

McCaughey, Claire

1984 A Survey of Arts Audiences Studies: A Canadian Perspective, 1967-1984. Ottawa: The Canada Council.

McConnell, David

2000 Implementing Computer Supported Cooperative Learning. London: Psychology Press.

Melton, Arthur

1935 Problems of Installation in Museums of Art. New Series, 14. Washington, DC: American Association of Museums. http://dx.doi.org/10.1037/11526-000

Milekic, Slavko

2010 Gaze-tracking and Museums: Current Research and Implications. In Museums and the Web 2010: Proceedings. Jennifer Trant and David Bearman, eds. Toronto: Archives and Museum Informatics. http://www.archimuse.com/mw2010/papers/milekic/milekic.html, 
accessed December 1, 2010.

Paccagnella, Luciano

1997 Getting the Seat of Your Pants Dirty: Strategies For Ethnographic Research on Virtual Communities. Journal of Computer-Mediated Communication 3(1). http://dx.doi.org/10.1111/j.1083-6101.1997.tb00065.x

Parham, Angel Adams

2005 Internet, Place, and Public Sphere in Diaspora Communities. Diaspora 14(2/3):349-380. http://dx.doi.org/10.1353/dsp.0.0020

Pearce, Susan, ed.

1995 Art in Museums. New Research in Museum Studies: An International Series, 5. London: Continuum International Publishing Group.

Rentschler, Ruth, and Eva Reussner

2002 Museum Marketing Research: From Denial to Discovery? HEC Montréal Working Paper Series. November 2002.

Robinson, Edward

1928 The Behavior of the Museum Visitor. Washington, DC: American Association of Museums.

Rybas, Natalia, and Radhika Gajjala

2007 Developing Cyberethnographic Research Methods for Understanding Digitally Mediated Identities. Qualitative Social Research 8(3). http://www.qualitativeresearch.net/index.php/fqs/article/view/282/, accessed November 20, 2013.

Schiele, Boris

1993 Creative Interaction of Visitor and Exhibition. Visitor Studies 5(1):28-56. http://dx.doi.org/10.1080/10645579209445758

Silverstone, Roger

1989 Heritage as Media: Some Implications for Research. In Heritage Interpretation. vol. 2: The Visitor Experience. David Uzzell, ed. Pp. 138-148. London, UK: Belhaven Press.

Solas, Nate 
2010 Hiding our Collections in Plain Site: Interface Strategies for "Findability." In Museums and the Web 2010: Proceedings. Jennifer Trant and David Bearman, eds. Toronto: Archives and Museum Informatics. http://www.archimuse.com/mw2010/papers/solas/solas.html, accessed December 1, 2010 .

Soren, Barbara

1995 Best Practices in Creating Quality Online Experiences for Museum Users. Canadian Heritage Information Network. Museum Management and Curatorship 20(1):131-148. http://dx.doi.org/10.1016/j.musmancur.2005.03.001

Van den Heuvel, Charles, Sandor Spruit, Leen Breure, and Hans Voorbij

2010 Annotators and Agents in a Web-based Collaboratory around Cartographical Collections in Cultural Heritage Institutions. In Museums and the Web 2010: Proceedings. Jennifer Trant and David Bearman, eds. Toronto: Archives \& Museum Informatics. http://www.archimuse.com/mw2010/papers/heuvel/heuvel.html, accessed October 25, 2011.

Villaespesa, Elena

2013 Diving into the Museum's Social Media Stream. Analysis of the Visitor Experience in 140 Characters. MW2013: Annual Conference of Museums and the Web, April 17-20, Portland, OR. http://mw2013.museumsandtheweb.com/paper/diving-into-the-museumssocial-media-stream/, accessed June 1, 2013.

Vom Lehn, Dirk, Christian Heath, and Jon Hindmarsh

2002 Video-based Field Studies in Museums and Galleries. Visitor Studies Today 5(3):15-23. http://informalscience.org/research/ic-000-000-008-307, accessed November 21, 2013.

Wilson, James

2011 Behind the Scenes of the Museum Website. Museum Management and Curatorship 26(4):373-389. http://dx.doi.org/10.1080/09647775.2011.603934

Wong, Amelia S.

2011 Ethical Issues of Social Media in Museums: A Case Study. Museum Management and Curatorship 26(2):97-112. http://dx.doi.org/10.1080/09647775.2011.566710

Zorloni, Alessia 
2010 Managing Performance Indicators in Visual Art Museums. Museum Management and Curatorship 25(2):167-180. http://dx.doi.org/10.1080/09647771003737273

Natalia Grincheva is a Ph.D. researcher at the Centre for Interdisciplinary Studies in Society and Culture (CISSC) at Concordia University in Montreal. Her doctoral research encompasses new museology, cultural diplomacy, and social media. Her project focuses on the use of social media in museums' international outreach and diplomatic activities and aims to evaluate the impact of cultural diplomacy programs that are implemented online in a museum context. Her most recent publication is 'Psychopower' of Cultural Diplomacy in the Information Age (Los Angeles: Figueroa Press, 2013), published by the USC Center on Public Diplomacy as part of its Series Perspectives on Public Diplomacy.

http://dx.doi.org/10.14434/mar.v8i1.3187 